\title{
Should I Give Grandma An iPod For Christmas? Music Consumption Behavior In The Digital Age
}

Joshua T. Coleman, MBA Student, Western Kentucky University, USA Stephen B. Castleberry, Ph.D., University of Minnesota Duluth, USA

\begin{abstract}
Ryan has to help an aspiring tribute artist learn how to best market his music to the elderly market. He does so by collecting data via internet research, sales analysis, field observation, and a survey. The case requires students to evaluate the quality of the research conducted and then provide marketing direction. The case could be used in the following undergraduate or graduate courses: marketing research, principles of marketing, marketing strategy, consumer behavior.
\end{abstract}

Keywords: Marketing Research; Music; Nostalgia; Marketing Strategy; Senior Citizen Income; Marketing Case Study

\section{INTRODUCTION}

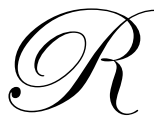

yan Joyner couldn't believe his luck. A paid marketing internship, located in the city where he wanted to spend his summer, and it was in the music industry, too. It couldn't get any better than that!

As a senior marketing major with a minor in music, Ryan had hopes of someday working in the music industry, perhaps as an agent or a marketing manager. And this internship, if he could do a good job, might provide just the entrée he was looking for.

Ryan was going to be interning with Mark Lyons ${ }^{1}$, a young guitarist and independent artist. Mark is a guitar tribute artist of Lloyd Smith, a Country Music Hall of Fame inductee and one of the most recorded country music guitarists of all time (a tribute artist is someone who impersonates a famous and usually deceased artist).

Lloyd Smith spent much of his early performing years as a very busy studio musician, playing for such names as Elvis Presley, Brenda Lee, Patsy Cline, The Browns, Jim Reeves, Eddy Arnold, and the Everly Brothers. Smith went on to launch a solo career, releasing dozens of albums and hitting "gold record" status, selling over a million copies of one piece. Smith died in 1997, although his fan base continues to purchase his many albums.

Due to Lloyd Smith's recognition, especially among senior citizens, Mark employs nostalgia marketing to promote Mark's own four albums featuring Smith's music. He promotes his work through his website, retail stores around his hometown of Nashville, Tennessee, and concerts throughout the southeastern United States.

Mark seemed pretty cool when Ryan met him during the interview. He indicated that he needed a lot of marketing help, since he liked to perform music, not deal with the "marketing and management" side of his business. When asked, Mark said he would really like Ryan to help him learn how to better market his business. Mark was wondering if he should move to more of a digital format so customers could download songs directly from the internet, since that's the wave of the future. Of course, many of Mark's customers were senior citizens and

\footnotetext{
1 The case is based on an actual artist and all facts and figures are accurate. However the name of the artist and the original artist, as well as some minor details about other artists and the songs played have been changed to protect anonymity.
} 
he wasn't sure if they would like to buy music digitally off the web. And was there any way to increase Mark's sales of his CDs on the Internet?

As the internship began, Ryan decided to use some techniques he learned in his marketing and marketing research courses. First, he wanted to do some background research on the industry and the elderly market (which Mark indicated to be his primary audience). Then he would conduct some primary marketing research.

\section{BACKGROUND INDUSTRY RESEARCH}

Mark learned a lot about the senior market and the music industry.

\section{The Senior Citizen Market}

Senior citizens are the most rapidly expanding group in the nation (Savi, et al. 2008). Traditionally defined as those 65 and older, this population subset grew from 3.1 million people in 1900 to over forty million in 2010 (Hobbs and Stoops 2002, Census Briefs 2010). The age distribution of the entire U.S. population has shifted from the relatively young to the relatively old, with the senior citizen segment growing at a rate of $15.1 \%$ from 2000 to 2010, compared to a growth rate of $2.6 \%$ for those under 18 (Census Briefs 2010).

The senior citizen percentage of total U.S. population is expected to increase from $13 \%$ in 2000 to over $20 \%$ by the year 2050 (U.S. Census Bureau 2008), making one of every five people in the country above the age of 65 , as opposed to one of every ten people in 1970 (Oumlil and Williams 2000). This rapid rise in population could continue to the point at which there are twice as many senior citizens as there are 18-34 year-olds by the year 2025 (U.S. Census Bureau 2008).

Perhaps the most well known adjunct to this rise in the population of senior citizens is the aging of the baby boomers, people born between the years of 1946 and 1964. This large group started reaching the age of 65 in 2011. Baby boomers began turning 50 in 1996 at the rate of nearly 300,000 people every month (Henderson 1998). There are more than twice as many baby boomers as there are current senior citizens, a number that will greatly impact the overall proportion of people aged 65 and older in the years to come (U.S. Census Bureau 2008).

In the United States, senior citizens age 65 and up have the most discretionary income of any age group, with some estimates allotting them half the nation's disposable income, while others indicate that this group spends up to $\$ 200$ billion each year (Oumlil and Williams 2000.) In fact, senior citizens spend nearly $\$ 150$ million every day (Tootelian and Varshney 2010).

While sensitive when it comes to costs, the elderly are typically more likely to pay a higher price when special attention is received. As one study points out, "products tailored to senior consumers should be simple, userfriendly and easy for people with physical limitations to use" (Savi, et al. 2008, p. 319). Similarly, as technology began to enter the marketplace, the elderly tended to experience difficulties when presented with rapidly paced, complex information or data given in large quantities (Gorn, et al. 1991).

\section{Nostalgia Marketing}

Nostalgia is a preference (a liking, a positive attitude) toward things from earlier in one's life, or a preference for things about which the person has learned. In order to feel nostalgic toward something, one must be separated from the time for which he or she yearns (Sierra and McQuitty 2007).

As people age, they often yearn for their past or feel a longing for possessions or experiences associated with their past. Group identity can also play a role in the shaping of nostalgia, as this yearning for the past can be shared by members of the same time period or experiences for which one is longing (Goulding 2002). Unity between individuals who share similar experiences can be formed, giving way to new group identities based solely around nostalgic feelings (Havlena and Holak 1991). Furthermore, being a part of a group with similar pasts helps shape individual identity and can impact the personal nostalgia one experiences by adding to the collection of one's repertoire of the past (Sierra and McQuitty 2007). 
For marketers, the fact that a large number of people wish to revisit the past, especially senior citizens, who are more prone to nostalgia, provides ample reason to pursue the idea of nostalgic marketing (Sierra and McQuitty 2007). Selling products that allow users to experience a time already passed appeals to nostalgic consumers. People may wish to purchase items that remind them of their past, in an effort to preserve or bring back their past (Motley, et al. 2003). It appears that this desire for products not found in the abundance they once were, gives many customers an even stronger desire to purchase (Reed 2002).

\section{The Music Market}

Digital music, or music that can be consumed through digital formats, is one of the most rapidly expanding areas in today's economy (Beer 2008). Consumers are storing thousands of songs onto portable music players as opposed to bookshelves and CD racks. Some groups, such as the elderly, are not adapting to this new kind of library as quickly as other, younger populations (Beer 2008).

The senior citizen market is starting to become acclimated to more current styles of music (e.g., rock, country, rap, etc.). One author even predicated that "popular music is so pervasive that efforts to bring the old tunes back to life face stiff competition" (Ward 2003, p. 9). This could be a problem, since Mark's music is the "old tunes" of the 1950's.

\section{The Internet}

Internet sales have increased significantly, with over $\$ 100$ billion being spent annually (Kopytoff 2006).

Thirty-one percent of the elderly population has never used the Internet; conversely, 70 percent of baby boomers have (McGuire 2005). Internet usage is lowest among senior citizens (Bucy 2000), with one study indicating that the only group using the Internet less is probably prisoners (Pepper 2002). Even though the next generation of senior citizens (baby boomers) possesses much more fluency with Internet usage, there is still a \$200 billion market that does not (Joseph and Stone 2005).

Of those seniors who are online, some of the more common activities utilized by the age group are shopping and research. By contrast, the younger generations are using the Internet much more for social and entertainment purchases (Jones and Fox 2009). Furthermore, one study reveals that senior citizens who do purchase products online only do so once or twice a year (Reisenwitz, et al. 2007).

Some members of the senior citizen population simply have no interest in using the Internet. Avoidance arises from a variety of sources, including an overall lack of experience and understanding (Reisenwitz, at al. 2007). Despite the fact that the elderly, due to a general decline in mobility and health, could potentially gain the most from utilizing the Internet (Priest, et al. 2007), one study indicated that a large majority of the elderly do not think they are missing out on anything by not using the Internet (Guynn 2002).

The senior citizens who are online also suffer from an overall lack of confidence when using the Internet, especially when compared to younger users (AARP 2000). The elderly tend to become lost and confused when going online, a problem that only increases their discomfort to a greater degree (Slone 2003). They use more caution when online than do users familiar with the Internet, reading all the information presented on web pages and clicking every link, most of which younger users would know to skip (Saranow 2004). Because they are less confident online, senior citizens are less likely to purchase online, with women displaying significantly less surety than men (Reisenwitz, et al. 2007).

Of particular interest to this research, one study by Reisenwitz, et al. (2007) found that consumers prone to nostalgia showed significantly different results than those not affected by nostalgia. More specifically, those more heavily nostalgic used and accessed the Internet less, shopped and purchased online less, exhibited less experience using the Internet, and felt less comfortable online than those not prone to nostalgia. It can be surmised, then, that while the elderly population and the Internet market are both rising rapidly, senior citizens prone to nostalgia display an inverse relationship to online sales. 


\section{SALES RECORDS ANALYSIS}

Having a better feel for music, the internet, and the senior citizen market, Ryan decided it was time to start poring over Mark's last two years of sales data. While Mark didn't have a complete database, as Ryan had hoped, Mark was able to provide some basic data, including the locations at which his CDs were sold and the contribution to overall profit each method incurred. Ryan learned that Mark only sells his music in CD format at this time.

Mark's accounting system divides sales locations into seven categories: complimentary (distributed at no charge to the receiver), general (distributed through Mark with his personal contacts and friends), mail order, web order, performances, retail (sales at CD signings at malls and record stores), and church (CDs sold at Mark's home church, where Mark has a dedicated following). Complimentary sales, obviously, contribute nothing to overall income. CDs sold at performances provide highest contribution to income at $\$ 15.00$, while those sold at retail venues provide the lowest contribution of $\$ 7.00$. All other locations/methods of selling contribute roughly $\$ 12.00$ per CD to income. See Table 1 for breakdowns in profits.

Table 1: Mark Lyons Sales Records For the Most Recent Two-Year Period

\begin{tabular}{|l|c|c|c|c|c|}
\multicolumn{1}{c|}{} & \multicolumn{1}{c|}{ Total CDs } & \% of Total & $\begin{array}{c}\text { Average } \\
\text { Contribution }\end{array}$ & $\begin{array}{c}\text { Estimated } \\
\text { Profits }\end{array}$ & \% of Total \\
\hline Complimentary & 140 & $3 \%$ & $\$ 0$ & $\$ 0$ & $0 \%$ \\
General & 303 & $8 \%$ & $\$ 12.00$ & $\$ 3,636.00$ & $9 \%$ \\
\cline { 2 - 7 } $\begin{array}{l}\text { Mail Order } \\
\text { Web Order }\end{array}$ & 162 & $4 \%$ & $\$ 12.00$ & $\$ 1,944.00$ & $5 \%$ \\
Performances & 223 & $6 \%$ & $\$ 12.00$ & $\$ 2,676.00$ & $7 \%$ \\
Retail & 1,063 & $26 \%$ & $\$ 15.00$ & $\$ 15,945.00$ & $41 \%$ \\
\cline { 2 - 7 } & 2,022 & $52 \%$ & $\$ 7.00$ & $\$ 14,154.00$ & $36 \%$ \\
\cline { 2 - 7 } & 62 & $2 \%$ & $\$ 12.00$ & $\$ 744.00$ & $2 \%$ \\
\hline
\end{tabular}

\section{FIELD OBSERVATION}

Now that Ryan had some sales history information, he knew that he needed to collect primary data. After talking to Mark, he decided to do some field observation. Mark granted permission for Ryan to engage in observational studies at two different locations at which he played guitar to promote his music. Mark chose two locations for this approach: a shopping mall (the Apple Barn) and a hotel (the Opryland Hotel), both of which were in Nashville, Tennessee. Next to Mark stood a sign reading, "Mark Lyons, Tribute Artist of Guitar Legend Lloyd Smith," with the names "Mark Lyons" and "Lloyd Smith" nearly the same size.

At the mall during the December holiday season, crowds are inevitably denser than at other times of the year. Lyons set up his promotional materials and played for roughly three hours to raise awareness of his music. His music could be heard anywhere from 50 to 100 feet away from the store, depending on the density of foot traffic and general mall noise.

Ryan sat on a bench about twenty feet away from Mark and kept records of how long consumers seemed to express interest in Lyons, an estimate of their age, their gender, and their race. Ryan also kept track of from which CD Lyons was playing music at the time consumers first expressed interest. He did this in order to attempt to ascertain whether or not individual songs could attract consumers more than others. However, no song played seemed to elicit more interaction with Lyons and sales of CDs. Also, Ryan noted who actually purchased Lyons's albums, but because the intentions for purchasing could not be known, this data turned out to be irrelevant as well. For example, someone may not have purchased Lyons's music because he or she already owned multiple copies of each CD. Such motivations could not be determined from observational studies.

Mark observed over a period of two hours. During this time, approximately 104 customers showed direct interest in Lyons by approaching his table, picking up his CDs up from his table, or speaking to him while he played. 
Of these, only 24 stayed for four minutes or longer. The majority of consumers remained for two to three minutes. Sixty-six people, over half, appeared to be of senior-citizen status, while only four looked to be younger than the age of 30 . While ages cannot be adequately defined from mere observation, the overall impression could not be denied that the elderly showed more interest than their younger counterparts. Similarly, 65 consumers were female, while only 39 were male. Race was observed as well, and the results were easy to interpret: $100 \%$ of observed consumers were Caucasian. See Table 2 for full results.

Table 2: Field Observation Results (Minutes $=$ Total time consumers expressed interest in Lyons)

\begin{tabular}{|l|c|c|c|}
\hline & Apple Barn (mall) & Opryland Hotel (hotel) & Combined Results \\
\hline Minutes & & & \\
\hline 1 & 14 & 11 & 25 \\
\hline 2 & 41 & 20 & 61 \\
\hline 3 & 25 & 5 & 30 \\
\hline 4 or more & 24 & 16 & 40 \\
\hline Age & & 2 & 2 \\
\hline$<15$ & 0 & 0 & 4 \\
\hline $16-30$ & 4 & 0 & 15 \\
\hline $31-45$ & 15 & 8 & 27 \\
\hline $46-60$ & 19 & 42 & 106 \\
\hline $61-75$ & 64 & 0 & 2 \\
\hline $76<$ & 2 & & 95 \\
\hline Gender & & 30 & 61 \\
\hline Female & 65 & 22 & \\
\hline Male & 39 & & \\
\hline
\end{tabular}

Three days later, Ryan used the same observation format, only this time at the hotel. Because the hotel was less crowded than the shopping mall during the holiday season, over the same period of two hours, Ryan observed just over half the amount of customers who expressed interest at the mall. Fifty-two people were observed with similar results to those found in the first observation.

Sixteen people stayed longer than four minutes, a greater proportion than discovered previously, but still did not represent the majority of those who stopped by. Most consumers expressed interest for only one to two minutes. Forty-two people appeared to be elderly, which is also a greater proportion than the results found at the mall. This could be due partly to the fact that, in general, younger families visit the mall more frequently than the hotel. Again, while exact ages cannot be determined from observational studies, the overwhelming impression is that it is the elderly that are interested in Mark's music. Also strikingly consistent, everyone observed was Caucasian.

Combining the results from both studies provided a rough average of the data. The average customer devoted slightly less than three minutes to Lyons's music. Sixty-nine percent of all observed customers appeared to be senior citizens, and the female to male ratio is almost exactly 60:40.

\section{SURVEY OF CONSUMERS}

While reviewing the data from the observation study, Ryan had a conversation with Mark. "What we need to do is to get some survey data from older adults," Ryan suggested. Mark thought about it, then answered, "Well, I'm okay with that. But I can't pay for any fancy studies. In fact, if you can find a free way to gather some data, I'm all for it."

Ryan rubbed his jaw. Just how was he going to conduct a survey without spending any money? While he was thinking, Mark spoke up, "How about just giving a survey out at my church? That way you could at least learn something, and it'd be free. What do you say?" 
Since Ryan didn't have any other ideas, he decided to follow Mark's suggestion. A questionnaire was distributed to two large classes at Mark's church on a Sunday morning immediately preceding the day's lesson. Because the classes are typically segmented by age group, one class provided a large sample of baby boomers while the other provided a large sample of senior citizens.

The questionnaire consisted of only four questions. The first question asked respondents to rank their preference for purchasing music from one to five, with one being the most preferred method and five being the least preferred method. Five choices were given that coincide with Lyons's methods of sales: in person, at retail stores; in person, at concerts/performances; online order; mail order; and telephone order. The second asked respondents to rank their music listening preference rather than their music purchasing preference on the same scale as the first question, one to five. The options given included cassette tape; compact disc (CD); live/at a concert; portable music player (iPod, MP3 player, etc.); and radio. This question was asked primarily to ascertain any differences between purchasing and listening preferences. For example, do consumers who do not like to purchase music through the Internet like to listen to music through digital methods? The third and fourth questions were merely demographic in nature, asking for gender and age. The age question was broken down into categories, ranging from under 44, $45-$ $54,55-64,65-74,75-84$, and 85 and up. Three of these categories roughly fall into the range of baby boomers (64 and below), and three categories pertain to senior citizens (65 and above).

Five different versions of the questionnaire were distributed with the only differences in each concerned the order of the responses to the first two questions. Because the first answer choice respondents see could inadvertently influence their answering decision, simply shuffling the order of the choices helped to reduce research bias.

Ninety-two completed surveys were collected. Concerning the age distribution, 14 respondents were designated as 44 and under, 18 as $45-54$, and 20 as $55-64$, comprising a total of 52 respondents whose age is 64 or below (falling into the baby boomer subset). Fifteen respondents were designated as being $65-74$ years old, 17 as $75-84$, and eight as 85 and up, comprising a total of 40 respondents considered to be senior citizens due to their ages being over 65 . Forty-nine of the respondents were female.

For the first question, respondents were asked to rank their preferences for venues for purchasing music by indicating which of the five response choices was their first choice, second choice, and so on. The range for each of the response options was 4 . Overall, the lowest median (indicating the highest preference) fell into the retail category at 1.5. Telephone was ranked the least preferred method of purchasing music with a median of 4 (5 indicating the lowest possible preference). See Table 3 for the full results.

Table 3: Frequency Distributions of Survey Results for Purchasing Preferences

\begin{tabular}{|c|c|c|c|c|c|c|}
\hline & & Retail & Concert & Online & Mail & Phone \\
\hline \multirow{5}{*}{ 禺 } & 1 & $46(50 \%)$ & $11(12 \%)$ & $18(20 \%)$ & $9(10 \%)$ & $8(9 \%)$ \\
\hline & 2 & $21(23 \%)$ & $27(29 \%)$ & $24(26 \%)$ & $10(11 \%)$ & $10(11 \%)$ \\
\hline & 3 & $12(13 \%)$ & $21(23 \%)$ & $14(15 \%)$ & $28(30 \%)$ & $17(19 \%)$ \\
\hline & 4 & $7(8 \%)$ & $13(14 \%)$ & $14(15 \%)$ & $27(29 \%)$ & $31(34 \%)$ \\
\hline & 5 & $6(7 \%)$ & $20(22 \%)$ & $22(24 \%)$ & $18(20 \%)$ & $26(28 \%)$ \\
\hline & & \multicolumn{5}{|c|}{$\begin{array}{l}\text { The first numbers denote the actual number of responses. The percentages represent the number of responses } \\
\text { divided by the total number of respondents. The total may not add to } 100 \text { due to rounding. }\end{array}$} \\
\hline
\end{tabular}

The second question asked respondents to once again rank their preferences from one to five for five options, one indicating the highest preference and five indicating the lowest preference, this time concerning their preferences for listening to music. The results are shown in Table 4. 
Table 4: Frequency Distributions of Survey Results for Listening Preferences

\begin{tabular}{|c|c|c|c|c|c|c|}
\hline & & Cassette & CD & Live & Digital & Radio \\
\hline \multirow{5}{*}{ 最 } & 1 & $8(9 \%)$ & $22(24 \%)$ & $13(14 \%)$ & $16(17 \%)$ & $33(36 \%)$ \\
\hline & 2 & $17(19 \%)$ & $28(30 \%)$ & $11(12 \%)$ & $12(13 \%)$ & $24(26 \%)$ \\
\hline & 3 & $15(16 \%)$ & $21(23 \%)$ & $23(25 \%)$ & $14(15 \%)$ & $19(21 \%)$ \\
\hline & 4 & $20(22 \%)$ & $15(16 \%)$ & $27(29 \%)$ & $21(23 \%)$ & $9(10 \%)$ \\
\hline & 5 & $32(35 \%)$ & $6(7 \%)$ & $18(20 \%)$ & $29(32 \%)$ & $7(8 \%)$ \\
\hline & & \multicolumn{5}{|c|}{$\begin{array}{l}\text { The first numbers denote the actual number of responses. The percentages represent the number of responses } \\
\text { divided by the total number of respondents. The total may not add to } 100 \text { due to rounding. }\end{array}$} \\
\hline
\end{tabular}

Ryan then recoded the data so that all responses from the first three age categories (under 44, 45 - 54, and 55 - 64) were collapsed into one new group (referred to as baby boomers) and all responses from the last three age categories (65-74, $75-84$, and 85 and up) into a second new group (referred to as senior citizens). Results are shown in Table 5.

Table 5: Median Ranking for Purchasing and Listening Preferences by Age Group

\begin{tabular}{|l|c|c|c|}
\hline & Baby Boomers & Senior Citizens & Total \\
\hline Purchasing preferences & & & 1.5 \\
\hline Retail & 1 & 2 & 3 \\
\hline Concert & 3 & 2 & 3 \\
\hline Online & 2 & 4 & 3 \\
\hline Mail & 4 & 3 & 4 \\
\hline Listening preferences & & & 4 \\
\hline Phone & 4 & 3.5 & 2 \\
\hline Cassette & 5 & 3 & 3 \\
\hline CD & 2 & 3 & \\
\hline Live & 4 & 3 & \\
\hline Digital & 3 & 5 & \\
\hline Radio & 2 & 2 & \\
\hline
\end{tabular}

Cross-tabulations were performed between the two age groups, baby boomers and senior citizens, to determine if preferences differed significantly for either preferences of where to buy music or preferred music format by age cohort. Of these tests, only three revealed any significant difference between the two subsets and their preferences $(\mathrm{p}<.05)$. Senior citizens preferred listening to cassette tapes $(42.5 \%)$ more so than baby boomers did $(15.38 \%)$. Baby boomers prefer to a much greater degree to purchase their music on the Internet $(61.54 \%$ to $25 \%, \mathrm{p}$ $<.001)$, and they also prefer listening to music through digital music methods significantly more than senior citizens $(36.54 \%$ to $22.5 \%, \mathrm{p}<.05)$. However, baby boomers still indicated only a mid-range preference toward digital music listening methods (median of 3, indicating it would be third of five choices); that is, even though baby boomers do prefer these categories more than senior citizens, it does not seem that baby boomers are using these methods widely.

Case questions:

1. Evaluate Ryan's background industry research. Does it seem appropriate? How could it be improved?

2. Evaluate Ryan's sales record research. Does it seem appropriate? How could it be improved?

3. Evaluate Ryan's field observation research. Does it seem appropriate? How could it be improved?

4. Evaluate Ryan's survey research. Does it seem appropriate? How could it be improved?

5. Based on the data provided by Ryan's research, how should Mark market his music? Provide as much detail as possible in your response and state any assumptions you are making. 


\section{AUTHOR INFORMATION}

Josh Coleman is pursuing his MBA at Western Kentucky University, where he graduated summa cum laude in 2009 with a Bachelor of Science in Marketing and where he currently works as an undergraduate admissions counselor. After earning his MBA, Josh plans to pursue his Ph.D. in Marketing. E-mail: josh.coleman410@gmail.com

Stephen B. Castleberry, Ph.D. has been a Professor of Marketing in the Labovitz School of Business and Economics, University of Minnesota Duluth since 1992, where he teaches marketing and business ethics courses. Prior to joining UMD he held positions at Northern Illinois University (UARCO Professor of Sales and Marketing endowed chair) and the University of Georgia. He has also held administrative posts at both NIU and UMD. Dr. Castleberry has published many refereed journal articles in national publications, is the co-author of Selling: Building Partnerships, and is the past marketing editor of the Journal of Applied Business Research. E-mail: scastleb@d.umn.edu. Corresponding author.

\section{REFERENCES}

1. AARP (2000), "AARP National Survey on Consumer Preparedness and E-Commerce: A Survey of Computer Users Age 45 and Older," AARP Research Group, Washington, DC, March (available at www.aarp.org/research/reference/public opinions/aresearch-import-189.html

2. Beer, David (2008), "The Iconic Interface and the Veneer of Simplicity: MP3 Players and the Reconfiguration of Music Collecting and Reproduction Practices in the Digital Age," Information, Communication, and Society, 11 (February), 71-88.

3. Bucy, Eric P. (2000), "Social Access to the Internet," Harvard International Journal of Press/Politics, 5 (Winter), 50-61.

4. Census Briefs (2010) “Age and Sex Composition: 2010,” U.S. Department of Commerce, Economics and Statistics Administration, U.S. Census Bureau.

5. Gorn, Gerald J., Marvin E. Goldberg, Amitava Chattopadhyay, and David Litvak (1991), "Music and Information in Commercials: Their Effects with an Elderly Sample," Journal of Advertising Research, (October/November), 23-32.

6. Goulding, Christina (2002), "An Exploratory Study of Age Related Vicarious Nostalgia and Aesthetic Consumption," Advances in Consumer Research, 29, 542-546.

7. Guynn, Jessica (2002), "Internet Connects Seniors to Rest of the World," Knight Rider Tribune Business News, (May).

8. Havlena, William J. and Susan L. Holak (1991) "The Good Old Days: Observations on Nostalgia and its Role in Consumer Behaviour," Advances in Consumer Affairs, 18, 232-329.

9. Henderson, Carter (1998), "Today's Affluent Oldsters: Marketers See Gold in Gray," The Futurist, (November), 19-23.

10. Hobbs, Frank and Nicole Stoops (2002), "Demographic Trends in the 20 ${ }^{\text {th }}$ Century," U.S. Census Bureau, (November).

11. Jones, Sydney and Susannah Fox (2009), Generations Online in 2009, Pew Internet \& American Life Project, an initiative of the Pew Research Center, as viewed on October 24, 2011 at: http://pewinternet.org/Reports/2009/Generations-Online-in-2009.aspx

12. Joseph, Nadine, and Brad Stone (2005), "Diagnosis: Internet Phobia," Newsweek, (April), 74.

13. Kopytoff, Verne (2006), "Internet Holiday Buying Up 26\%; Bricks-and-Mortar Retailers Increasing Their Online Profile," San Francisco Chronicle, 30 (December).

14. McGuire, S. (2005), "Get Ready for Next-Generation Seniors," Medical Marketing \& Media, 40, 24.

15. Motley, Carol M., Geraldine R. Henderson, and Stacey Menzel Baker (2003), "Exploring Collective Memories Associated with African-American Advertising Memorabilia: The Good, the Bad, and the Ugly," Journal of Advertising, 32, 47-57.

16. Oumlil, A. Ben. and Alvin J. Williams (2000), "Consumer Education Programs for Mature Consumers," The Journal of Services Marketing, 14, 232-243.

17. Pepper, J. (2002), "Wired and Retired: Assisted Living Residents Go Online," Nursing Homes: Long Term Care Management, 51, 60. 
18. Priest, Lee, L. Nayak, and I. Stuart-Hamilton (2007), "Website Task Performance by Older Adults," Behavior and Information Technology, 26 (May-June), 189-195.

19. Reed, Americus II (2002), "Social Identity as a Useful Perspective for Self-Concept-Based Consumer Research," Psychology and Marketing, 19, 235-266.

20. Reisenwitz, Tim, Rajesh Iyer, David B. Kuhlmeier, and Jacqueline K. Eastman (2007), “The Elderly’s Internet Usage: An Updated Look," Journal of Consumer Marketing, 24, 406-418.

21. Saranow, J. (2004), "Consumer Technology: Memo to Web Sites: Grow Up! As More Older Consumers Go Online, Online Operators Would Do Well to Stop Thinking So Young," Wall Street Journal, (November).

22. Savi, Fatma Zehra, Nadir Ateşoğlu, and Mürtaza Önal (2008), "Consumers at the Age of 65 and Older," The Business Review, Cambridge, 9 (Summer), 316-321.

23. Sierra, Jeremy J. and Shaun McQuitty (2007), "Attitudes and Emotions as Determinants of Nostalgia Purchases: An Application of Social Identity Theory," Journal of Marketing Theory and Practice, 15 (Spring), 99-112.

24. Slone, D.J. (2003), "Internet Search Approaches: The Influence of Age, Search Goals, and Experience," Library \& Information Science Research, 25, $403-418$.

25. Dennis H. Tootelian and Sanjay B. Varshney (2010), "The grandparent consumer: a financial "goldmine" with gray hair?", Journal of Consumer Marketing 27/1 (2010) 57-63.

26. U.S. Census Bureau (2008), "Current Population Reports," Intercensal Estimates of the United States Resident Population by Age Groups and Sex.

27. U.S. Census Bureau (2009), “Table 2. Reported Internet Usage for Individuals 3 Years and Older, by Selected Characteristics: 2009, Current Population Survey (CPS) October 2009".

28. Ward, Marilyn (2003), "Where, Oh Where, Have the Good Old Songs Gone," The Futurist, (NovemberDecember), 8-9. 


\section{TEACHING NOTES}

\section{Case Questions}

\section{Evaluate Ryan's background industry research. Does it seem appropriate? How could it be improved?}

It seems that Ryan covered most of the bases when doing background research. The data seems fresh and appropriate. He apparently utilized most free public information sources.

It could have been improved by looking at proprietary sources of information, perhaps at a public library that offers free access to its patrons. This might include such sources as industry surveys, information about publically traded record companies, etc. For example, GMID has a number of reports that would help Ryan's marketing efforts, such as:

- $\quad$ “The World of Digital Music \& Consumers: An Update,” January 25, 2010.

- $\quad$ "The Swing Generation: Marketing to the Over 65's" January 2, 2007.

- " Nostalgia - Aiming at the Heart of Your Consumer," November 22, 2007.

- “iPods not Allowed: Retro Technology Lives On,” June 6, 2009

Mark did not consider life expectancy. The life expectancy numbers have changed drastically and are different even for people born just years apart. Life expectancy information should have been collected in order to better gauge not only the potential size of the market, but for how long that market will be viable.

Also, as Ryan looked at growth projections for the senior market over the next 20-50 years, it is important to realize that not all "over 65" people will find Mark's music appealing. One has to remember, the product/brand that Ryan is trying to promote, has a limited audience. That is, if someone didn't grow up in the era when Lloyd Smith was performing, they wouldn't necessarily like his music just because they have turned 65 . An easy way to see this is to look at a 22 year old today ... when that 22 year old turns "senior" status at 65 , there is no reason to expect that her interests in type of music will necessarily change. Her nostalgia will be for what she listens to today. Thus, projections of rapid growth in the senior market over the next 25 years don't necessarily mean that Mark's music will be in more demand.

Nostalgia market is very significant as research shows people are generally willing to spend more money for the nostalgia feeling. Ryan should have explored this in more detail. For example, what years exactly was Lloyd Smith most popular? Where was his music played the most? Who are the people who would have been most exposed to him and would have the greatest chance of liking his music? With this information, for example, Ryan could have pinpointed the range of years when these people would have been born, and knowing the life expectancy of those birth years could have further defined the size of his target market.

Finally, Ryan could have investigated a bit more with regard to nostalgia to determine under what conditions a senior citizen will purchase the music of a tribute artist, as opposed to just purchasing music from the original artist. That is to say, Mark Lyons' CDs are his, and not those of Lloyd Smith - it could be that nostalgia seekers are looking for Smith's CDs, not Lyon's CDs. And remember that consumers can still purchase Lloyd Smith's original records.

\section{Evaluate Ryan's sales record research. Does it seem appropriate? How could it be improved?}

For many cases in college marketing courses, students are provided with elaborate spreadsheets, loaded with timely and useful information. Ryan, on the other hand, was working in the real world of small company marketing, and had very little information with which to work.

The analysis shown in Table 1 is a good start at evaluating Mark's sources of sales revenue. Ryan can inform Mark as to which channel provides the most contributions, and as such, perhaps where to spend his efforts 
and time. Naturally, if Ryan had access to more complete information, then he could conduct more sophisticated data analysis, including computing regression analysis to see what factors (e.g., age, gender, did the purchaser already have original music from Lloyd Smith, was the purchaser a fan of Lloyd Smith, or did she just enjoy Mark's music without really knowing of Lloyd) were more important contributors to sales and/or profits.

Ryan should also investigate what opportunities Mark may be missing. Rather than focus solely on those channels that bring in the most profit, Ryan could suggest ways to improve the other channels that may not be as beneficial right now. One example of this would include web orders - though this channel only brings in $7 \%$ of Mark's profits now, this may be a good opportunity to investigate when looking to expand his market beyond that of Internet-reluctant senior citizens.

As an aside, some students will probably comment that Mark isn't making much money selling CDs. From classroom and textbook examples, they are often used to thinking about large, multinational firms that have sales in the billions of dollars each year. Yet, the truth is that there are many businesses in America that have incomes that aren't out of line with these figures. Often these individuals have created startup businesses that they are hoping to expand over the years. The incomes shown in this Table represent only one source for Mark, who also has a fulltime job in another industry.

\section{Evaluate Ryan's field observation research. Does it seem appropriate? How could it be improved?}

Ryan tried to collect quick and inexpensive information to help learn more about Mark and his marketplace. It is good that he chose several different venues to conduct his research, so that he could assess the impact of location on the results.

Ryan could have improved his data collection by having another person record the behavior of each passerby, to insure that everyone was measured. With an additional person, Ryan could have gathered information on each person, including such items as the following (was the person alone or with friends, did the person have someone with him/her that seemed disinterested or interested in Mark, etc.). An additional recorder could also help record information about those who chose not to stop by and visit with Mark [their age, gender, race, ethnicity, etc.]. So, why didn't Ryan do more? It was simply a factor of the cost of hiring more people.

Ryan could have also conducted similar observation research at the sales tables at one of Mark's concerts.

Of course there is the possibility that some of the data collected by Ryan was biased or inappropriately measured. For example, age judgments made by Ryan may be inaccurate. This can have an impact, as explained earlier, as people born in different years have different life expectancy based on their birth place, conditions, genetics, medical advances, etc.

Another potential bias for the mall data is the fact that the data was collected during a holiday season. Although this is a good time to promote Mark's CDs, as there are more shoppers, actual interest displayed in Mark's presence could have been impacted by the holiday rush. For example, what if some interested people were in a hurry to do the holiday shopping, and just didn't feel like they had time to stop right then and talk to Mark? What about people who generally would not be interested but just paid attention to Mark's performance as their spouses were Christmas shopping in a store nearby?

Ryan should also keep in mind that the ratio of males to females in the senior citizen market is not 50/50. He should note this when analyzing the data with regard to the ratio of males/females in the field observation study.

The data collected should be cross tabulated to better understand, for example, how many $50+$ females at the Apple Barn expressed interest towards Mark's performance for more than three minutes.

The main purpose of conducting the field observation was to verify Mark's insistence that his target audience was comprised of the elderly. Ryan needed some sort of proof, no matter how inexpensively it was obtained, that a large proportion of Mark's customers are indeed senior citizens. Were Ryan seeking to identify and 
quantify an accurate profile of Mark's ideal customer, field observation may not have been the best option; merely seeking to verify that Mark caters to senior citizens was a valid objective for this type of field observation.

Just a note: when analyzing the results, Ryan should focus on percentages, not counts of people.

\section{Evaluate Ryan's survey research. Does it seem appropriate? How could it be improved?}

The first step in analyzing the appropriateness of Ryan's survey research is to validate the quality of his questionnaire. If Ryan distributed a poorly constructed questionnaire, the results would be hard to identify as accurate. Also, if the questionnaire contained biased answers, the results would be difficult to analyze. In Ryan's case, he kept his survey short by asking only two non-demographic questions. To answer the fallibility of bias, Ryan distributed five versions of his questionnaire, changing the order of the answers each time.

One could argue that surveying only people in a church would result in biased results, since the potential market for music is more than the population of those who attend this denomination and go to this particular church. For example, sales from his church only represent $2 \%$ of his profits. Furthermore, the study could very well be biased since the church chosen was where Mark attends. Even though a promise of confidentiality was given, it is at least possible that some respondents would connect the issues raised in the survey with Mark, and then try to give answers that they think he would like to see.

So, is the data useless? Probably not. But Ryan should check the results against any published studies that indicate preferences of music by type, age, and gender. For example, here is one source of information Ryan could use: The Music Business \& Recording Industry, by Geoffrey Hull, Thomas Autchison and Richard Strasser (2010), New York: Routledge Books.

To summarize, this is primarily a situation of Ryan doing the best job he could with the limited resources available to him.

\section{Based on the data provided by Ryan's research, how should Mark market his music? Provide as much detail as possible in your response and state any assumptions you are making.}

Clearly, Mark has some difficult marketing challenges. According to research done by Ryan, those who are prone to nostalgia do not use the Internet much. That, coupled with the fact that the elderly don't use the Internet much, is going to make it hard for Mark to ramp up his sales on the Internet. That doesn't mean he should abandon having an Internet presence, however. Children of senior citizens often shop for their parents, either for gifts, or on behalf of the senior citizens. Also, research does show that there is increase in Internet usage as baby boomers rise to senior citizen status. So, even though there won't be a lot of senior citizens cruising his site, a number of Internetsavvy consumers may be doing so, buying on behalf of those senior citizens.

Another issue facing Mark is a primary market that consists of an aging senior citizen population. When those senior citizens die, who will take their place as purchasers of Mark's music? Mark should act now to avoid future disappointing sales. One option would be to choose a secondary market to target with his music. The music can be his current offering of Lloyd Smith-type music, but it is unclear if a younger audience will appreciate this style. Another option is to offer the secondary market a different type of music. Mark appears to be a talented musician, and can perhaps modify his sound to attract the interest and attention of a younger audience.

A plethora of opportunities are opened when looking at the idea of modifying his music for a younger audience. For example, as instrumental music seems to have decreased in popularity over the last few decades, Mark could embrace today's musical preferences and add vocals to his music. Another idea would be to start writing music that is more in line with today's popular music. If Mark were to write his own material and play it with Lloyd Smith's style, he may be able to branch out to a new market while still maintaining his link to Smith's legacy.

Mark should consider how senior-citizen friendly his current marketing channels are. For example, if his website is hard to navigate for users uncomfortable with the Internet, he should redesign his website to appeal to 
these older users. Also, he could look again at his print materials to ensure that they are easy to read for users of all ages, making sure the text is not too small and that the wording is easy to understand.

Another option for Mark is to give more concerts to attract attention to his music. This could help gain sales in his primary market, and might help attract attention to a secondary market of younger listeners. It is possible that senior citizens are being driven to, and perhaps escorted by their children or younger friends to the concerts, and in this way, he can attract new listeners.

Mark might consider offering his music in cassette format. Yes, it is old technology, but his customers still want it. He might even be able to sell them at a premium price.

Mark might also want to tie up with some other tribute artists who play songs by legends belonging to Lloyd's time. The tie up would attract a similar crowd and all the participating artists could benefit by selling more to this market.

Finally, at retail locations and in concerts, senior citizens could be trained in how to use the internet to buy Mark's records online. The one to one interaction would help the senior citizens and baby boomers understand how the process works and the benefits of delivery at their residences.

\section{WHAT ACTUALLY HAPPENED}

This is based on an actual situation. Here's what actually happened from "Ryan's" own words:

Mark realized his need to expand his work beyond the southeast U.S. He worked with a theater-owning company that books acts similar to his in theaters all over the country. Mark ended up visiting over 70 cities at which he had never performed over an eight month period, increasing his customer base and sales along the way. He titled his show in a similar way to his marketing of performances in his hometown. "The Legacy of Lloyd Smith" featured his name almost serving as a sub-heading, ensuring the practice of nostalgic marketing.

Also, Mark distributed a brochure outlining all of his CDs as well as the track listings on each, to increase his concert goers' awareness of what he had to offer. This tactic allowed potential customers to know ahead of time exactly what they wanted, increasing the efficiency of sales at the merchandise table. This decreased the frustration of long waits and unsatisfied customers.

Coinciding with the start of his nationwide tour, Mark also created a Facebook page to increase his ability to connect with fans. At each of his shows, he would take pictures and video of the crowd, encouraging them to visit his Facebook page and giving them a reason to do so. The page allowed him to stay in touch with his customers after visiting their hometowns, to retain a connection with them for repeat sales and return visits in the future. Throughout the eight-month course of his tour, Mark gained over 1,000 fans.

In seeking to broaden his music library, Mark released a new CD a few months after his tour ended. The new CD featured songs by contemporary artists like Coldplay and Sarah McGlaughlin, as well as the artists who have been found on his previous recordings. Such a mix of artists is just one way Mark is reaching out to a younger audience while still satisfying his current market. Also, every song is played with the same "Lloyd Smith-technique" found on so many of Mark's recordings: no matter the age of the song he's recording, Mark is still staying true to Smith's signature style. 


\section{NOTES}

